\title{
Elastic Responses of a Composite Shell Structure Subjected to Impact Loading
}

\author{
Shiuh-Chuan HER*, Ching-Chun LIAO \\ Department of Mechanical Engineering, Yuan Ze University, Chung-Li, Taiwan \\ crossref http://dx.doi.org/10.5755/j02.ms.24910
}

Received 17 December 2019; accepted 17 June 2020

\begin{abstract}
This work investigated the elastic responses of a composite laminate shell subjected to a transverse low-velocity impact. The governing equation based on the equations of motion of both the impactor and target was developed to detetrmine the impact force. The displacement of the shell subjected to unit impulse loading was solved using the finite element method. A non-linear differential equation in terms of the indentation depth was derived by incorporating the Hertzian contact law and theory of convolution. Runge-Kutta method was employed to solve the non-linear integro-differential equation, leading to the determination of the impact force at the point of contact between the impactor and the composite shell. The elastic responses including the displacement and stress of the composite laminate shell were evaluated using the finite element method by exerting the impact force on the apex of the composite shell. Present approach was verified with the analytical, experimental and numerical results reported in the existing literatures. The influences of stacking sequence of the composite laminate shell on the impact responses were examined through a series of parametric studies. In addition, impact responses of the spherical shells with different materials such as steel, aluminum and glass were studied.

Keywords: composite shell, impact, Hertzian contact law, theory of convolution.
\end{abstract}

\section{INTRODUCTION}

Composite laminates are widely used in lightweight construction especially in aerospace, vehicle, ship and sport industries because of their high specific strength and specific stiffness ratios. One major disadvantage for composite laminates is that they are vulnerable to impacts caused by dropped tools, hailstones, runway debris, etc. [1]. While the induced damage is interior in the composite laminate especially for low velocity impact, the invisible damage may significantly decrease the integrity and reliability of the composite structure [2]. Delamination and matrix cracking are the most common failure modes in the composite laminate. The stiffness and strength of the composite can be significantly reduced due to the delamination, lead to a catastrophic failure of the composite structure [3]. Thus, it is important to conduct the impact analysis from the structural safety point of view. Many efforts have been made by researchers to study the influence of impact on the composite structure using analytical, numerical and experimental methods. Tagarielli et al. [4] and Schubel et al. [5] have performed experimental tests to investigate the dynamic responses of composite sandwich structures under transverse low velocity impact. Liu and Liao [6,7] employed the finite element analysis to investigate the failure mechanism of fiber reinforced composite laminate impacted by a sphere. He et al. [8] used elasto-plasticity theory to study the permanent indentation of the graphite fiber reinforced composite under low-velocity impact. Choi [9] studied the membrane effect and geometrical nonlinearity on the transient responses of cylindrical composite shell under transverse low-velocity impact using finite element method.

\footnotetext{
${ }^{*}$ Corresponding author. Tel.: +886-3-4638800; fax: +886-3-4558013.
} E-mail address: mesch@saturn.yzu.edu.tw (S.C. Her)
Zhang et al. [10] investigated the impact force, matrix cracking and delamination of cross ply composite laminate under low velocity impact using finite element software ABAQUS. Zhang and Zhang [11] studied the delamination of composites induced by a low-velocity impact. Habib et al. [12] examined the influence of impactor shape such as conical and hemispherical on the residual tensile modulus and damage resistance of nonwoven flax/epoxy composite. Puech et al. [13] analyzed the crack propagation and impact force of polypropylene biocomposites subjected to drop-weight impact using finite element method and high speed camera. Soto et al. [14] developed an efficient numerical simulation model to study the failure mode of thin ply composite laminates. Abir et al. [15] proposed a finite element model to investigate the impact damage and compressive strength of composites. Gliszczynski [16] employed both the numerical and experimental methods to investigate the failure of glass fiber reinforced polymer (GFRP) laminate under low velocity impact. Xiao et al. [17] presented an improved analytical model based on Eshelby's inclusion method to predict the interlaminar shear strength and evaluate the impact damage of composite laminates. Berton et al. [18] developed a multiscale damage model based on commercial finite element software ABAQUS incorporation with synergistic damage mechanics model to predict damage progression of matrix micro-cracking in carbon fiber reinforced polymer and glass fiber reinforced polymer composite materials subjected to low-velocity impact. Balakrishnan et al. [19] investigated the effects of processing conditions such as compression pressure and heating temperature on the impact response of glass/polyamide-6 (G/PA-6) composite. The damage and residual strength of post impact were examined using micro-CT and three-point bending tests, respectively. Hamamousse et al. [20] performed numerical simulation of impact on the orthogrid epoxy panels 
reinforced with short fibers using the nonlinear Hertz's contact model and Tsai-Wu failure criterion.

In this work, modified Hertzian contact law combined with Runge-Kutta method were employed to evaluate the contact forces during the loading and unloading periods of a composite shell induced by a transverse low-velocity impact. Finite element method was used to determine the impact behavior of the composite structure including the deformation and normal stress by applying the contact force on the impact point of the shell. The impact responses of the composite structure were validated with the analytical, experimental and numerical results reported in the existing literatures. The influences of the impactor mass and velocity and the stacking sequence of the composite laminate on the transient responses of the composite shell were investigated through a series of parametric studies.

\section{DERIVATION OF CONTACT FORCE}

In this work, a ball dropped on the top of a thin composite spherical shell was analyzed to study the impact responses. All the non-impulse forces were ignored in the impact analysis. Koller and Busenhart [21] proposed a model which integrated equations of motion from both the composite shell and ball to deduce the contact force. The methodology was adopted in this study to derive the contact force as follow [22].

The equation of motion for the ball is expressed as

$\ddot{z}=-F / m$,

where $z$ and $m$ are the displacement and mass of the ball, respectively; $F$ denotes the impact force exerted by the ball on the composite spherical shell, $\ddot{Z}$ represents the acceleration of the ball.

A shell subjected to an unit impulse load $\delta(t)$ at the apex, the displacement at the apex of the shell can be symbolically expressed as $w_{g c}(t)$. For the low-velocity impact, the deformation of the composite laminate shell is small and is considered as an elastic impact. The composite laminate shell responds with a linear elastic behavior during the impact, although the Hertzian contact force is non-linear with respect to the indentation depth. Thus, the theory of convolution can be employed to determine the linear elastic response of the composite spherical shell. When a contact force $F(t)$ varied with time is exerted on the top of the composite spherical shell, the deformation of the spherical shell at the contact point can be determined utilizing the theory of convolution as follow.

$\mathrm{w}_{\mathrm{c}}(\mathrm{t})=\int_{0}^{\mathrm{t}} \mathrm{F}\left(\mathrm{t}-\mathrm{t}^{\prime}\right) \cdot \mathrm{w}_{\mathrm{gc}}\left(\mathrm{t}^{\prime}\right) \mathrm{d \textrm {t } ^ { \prime }} \equiv \int_{0}^{\mathrm{t}} \mathrm{F}\left(\mathrm{t}^{\prime}\right) \cdot \mathrm{w}_{\mathrm{gc}}\left(\mathrm{t}-\mathrm{t}^{\prime}\right) \mathrm{d \textrm {t } ^ { \prime }}$.

Contact force between the impactor and target is the main concern in the impact analysis. In this work, the contact forces during the loading and unloading periods were calculated separately. In the loading process, the contact force is expressed according to the Hertzian contact law as follow:

Loading $F=k s^{3 / 2} ; 0<s \leq s_{m}$.
In the unloading process, the contact force is expressed according to the modified Hertzian contact law as follow [23]:

Unloading

$F=F_{m}\left[\frac{s-s_{0}}{s_{m}-s_{0}}\right]^{5 / 2}=k^{\prime} \cdot\left[s-s_{0}\right]^{5 / 2}$

$k^{\prime}=\frac{F_{m}}{\left[s_{m}-s_{0}\right]^{5 / 2}}$,

where $s$ represents the indentation during the contact. It can be calculated from the displacements of the spherical shell and ball.

$S=Z-W_{C}$,

$k$ denotes the contact stiffness. For a spherical shell with composite material, the contact stiffness $k$ is expressed as follow [24]:

$k=\frac{4}{3} \frac{1}{\left[\left(1-v_{b}^{2}\right) / E_{b}+1 / E_{y y}\right]}\left(\frac{r_{b} \cdot r_{s}}{r_{b}+r_{s}}\right)^{1 / 2}$,

where $r_{b}$ and $r_{s}$ are the radii of the ball and composite spherical shell, respectively; $E_{b}$ and $v_{b}$ are the elastic modulus and Poisson ratio of the ball, respectively; $E_{y y}$ is the Young's modulus of the composite spherical shell along the direction of normal to the fiber.

During the impact, the maximum contact force $F_{m}$ occurs at the maximum indentation of $s_{m}$. The permanent indentation $s_{0}$ in the loading and unloading processes can be written as

$$
\begin{array}{ll}
s_{0}=0 & s_{\mathrm{m}}<s_{c r} \\
s_{0}=s_{m}\left[1-\left(\frac{s_{c r}}{s_{m}}\right)^{0.4}\right] & s_{m} \geq s_{c r},
\end{array}
$$

where $s_{c r}$ denotes the critical indentation which is taken as $0.0083 \mathrm{~mm}$ for graphite fiber reinforced composite [25].

Eq. 5 and Eq. 2 can be rewritten as follow by taking the derivative with respect to time twice.

$$
\begin{aligned}
& \ddot{s}=\ddot{z}-\ddot{w}_{c} ; \\
& \ddot{w}_{c}(t)=\dot{F}(t) \cdot w_{g c}(0)+2 F(t) \cdot \dot{w}_{g c}(0)+\int_{0}^{t} F\left(t^{\prime}\right) \cdot \ddot{w}_{g c}\left(t-t^{\prime}\right) d t^{\prime}
\end{aligned}
$$

Substituting Eq. 1, Eq. 3, Eq. 4 and Eq. 10 into Eq. 9, results in the governing equations in terms of the indentation s for the impact analysis as follows:

During the loading period

$$
\begin{aligned}
& \ddot{s}(t)+\frac{3}{2} k \dot{s}(t) s^{1 / 2}(t) w_{g c}(0)+2 k s^{3 / 2}(t) \dot{w}_{g c}(0) \\
& +\frac{k}{m} s^{3 / 2}(t)+k \int_{0}^{t} s^{3 / 2}\left(t^{\prime}\right) \ddot{w}_{g c}\left(t-t^{\prime}\right) d t^{\prime}=0
\end{aligned}
$$

During the unloading period

$$
\begin{aligned}
& \ddot{s}(t)+\frac{2}{5} k^{\prime}\left[s(t)-s_{0}\right]^{3 / 2} \dot{s}(t) w_{g c}(0)+2 k^{\prime}\left[s(t)-s_{0}\right]^{5 / 2} \dot{w}_{g c}(0) \\
& +\frac{k^{\prime}}{m}\left[s(t)-s_{0}\right]+k^{\prime} \int_{0}^{t}\left[s\left(t^{\prime}\right)-s_{0}\right]^{5 / 2} \ddot{w}_{g c}\left(t-t^{\prime}\right) d t^{\prime}=0
\end{aligned}
$$


The initial conditions for Eq. 11 are $s(0)=0 ; \dot{s}(0)=v_{0}$, wher $v_{0}$ denotes the impact velocity.

Runge-Kutta method is employed to solve the governing Eq. 11 and Eq. 12, results in the determination of the indentation $\mathrm{s}$. The contact forces during the loading and unloading periods can be obtained by substituting the indentation into Eq. 3 and Eq. 4, respectively. The displacement at the apex of the composite shell can be calculated through the substitution of the contact force into Eq. 2.

\section{IMPACT ANALYSIS OF COMPOSITE LAMINATE STRUCTURE}

\subsection{Verification}

Two examples were presented to illustrate the applicability of the proposed approach by comparing the results with existing literatures.

Example 1: A composite laminate plate impacted by a ball.

The composite laminate used in the test example is graphite composite T300/934. The graphite composite is stacked as $[0 /-45 / 45 / 90]_{2 s}$. Table 1 presents the composite material properties. The dimensions of the rectangular laminate plate are $76.2 \mathrm{~mm}$ in length, $76.2 \mathrm{~mm}$ in width and $2.54 \mathrm{~mm}$ in width, respectively. The Poisson's ratio, elastic modulus, density and radius of the impactor are 0.3 , $72 \mathrm{GPa}, 2800 \mathrm{kgm}^{-3}$ and $6.35 \mathrm{~mm}$, respectively. ANSYS finite element software was used in this study. The mesh for the finite element analysis is plotted in Fig. 1.

Table 1. Graphite composite properties T300/934 [26]

\begin{tabular}{|c|c|c|c|c|c|}
\hline$E_{x x}$ & $E_{y y}$ & $G_{x y}$ & $v_{x y}$ & $v_{y z}$ & $\rho$ \\
\hline $145 \mathrm{GPa}$ & $10 \mathrm{GPa}$ & $5.7 \mathrm{GPa}$ & 0.3 & 0.3 & $1536 \mathrm{kgm}^{-3}$ \\
\hline
\end{tabular}

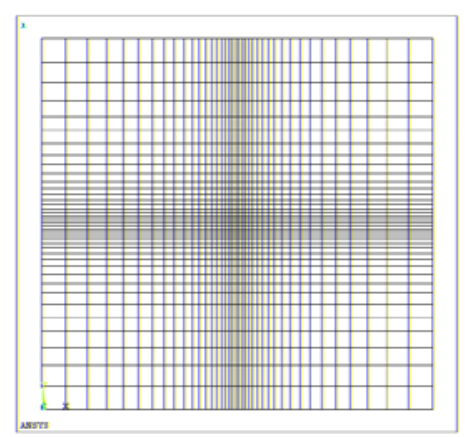

Fig. 1. Mesh for the finite element analysis of the laminate plate

The element type of Solid 46 with 8 nodes was used in this study. Total numbers of elements and nodes were 3200 and 4920, respectively. The composites laminate plate is subjected to an impulse loading $\delta(t)$ at the center. The time dependent of the displacement $w_{g c}(t)$ at the impact point of the laminate plate obtained by ANSYS is illustrated in Fig. 2. Substituting the displacement $w_{g c}(t)$ of the composite laminate plate at the impact point and impactor velocity $v_{0}$ into Eq. 11 and Eq. 12, the indentation of the composite plate induced by the impact can be determined using Runge-Kutta method. The contact forces during the loading and unloading periods can be obtained by substituting the indentation s into Eq. 3 and Eq. 4, respectively. Three different impactor velocities $38.1 \mathrm{~m} / \mathrm{s}$,
$25.4 \mathrm{~m} / \mathrm{s}$ and $12.7 \mathrm{~m} / \mathrm{s}$ were considered in this example. The contact forces for these three different impactor velocities are plotted in Fig. 3. The contact forces were compared with the results reported by Wu and Chang [26]. A good correlation was obtained between the present approach and Wu [26] as shown in Fig. 3.

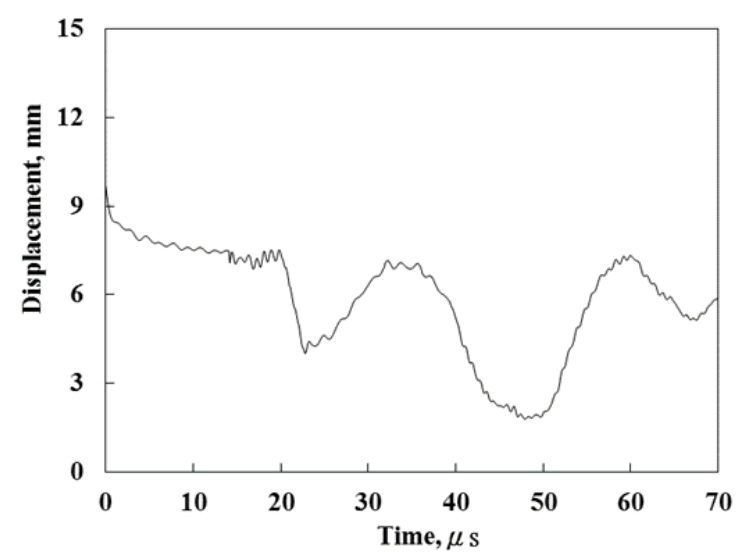

Fig. 2. Time dependence of the displacement $w_{g c}(t)$ for the laminate plate under impulse loading

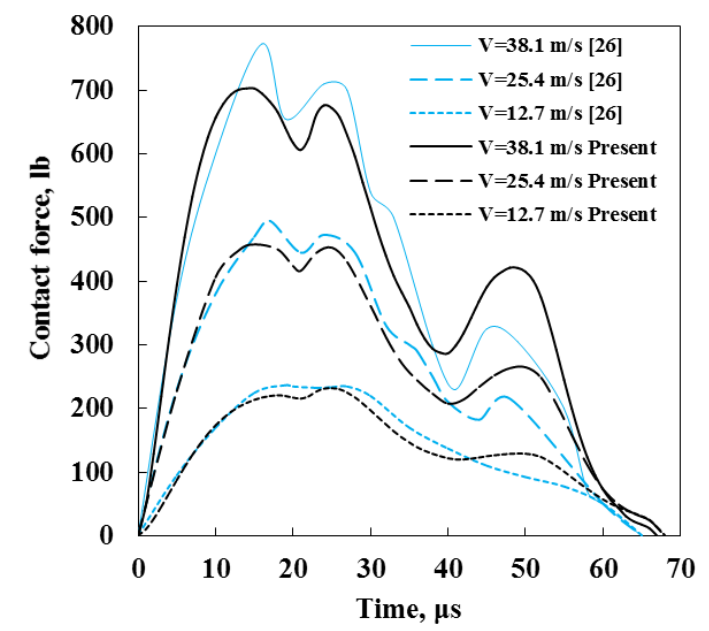

Fig. 3. Contact forces between the laminate plate and ball induced by the impacts of three different velocities

Example 2: An isotropic spherical shell impacted by a ball.

A glass spherical shell impacted by a steel ball was studied in this example as shown in Fig. 4.

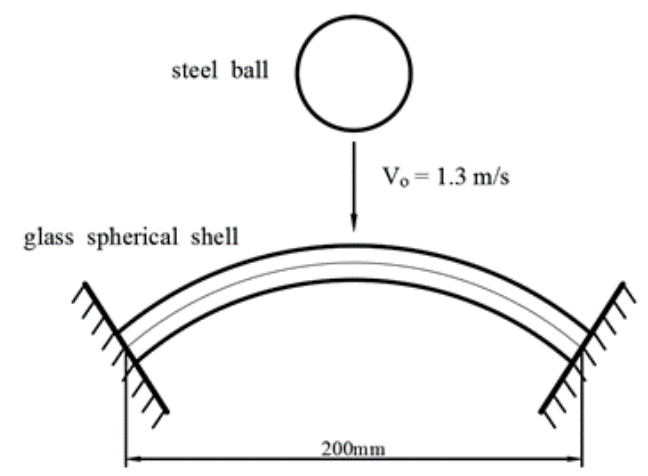

Fig. 4. A glass spherical shell impacted by a steel ball

The periphery of the shell is fixed. The radius and thickness of the spherical shell are $330 \mathrm{~mm}$ and $1.9 \mathrm{~mm}$, 
respectively. The radius and impact velocity of the ball are $3 \mathrm{~mm}$ and $1.3 \mathrm{~m} / \mathrm{s}$, respectively. The Young's modulus, density and Poisson's ratio of the glass are $69.7 \mathrm{GPa}$, $2492 \mathrm{~kg} / \mathrm{m}^{3}$ and 0.23 , respectively. The Young's modulus, density and Poisson's ratio of the steel are $206 \mathrm{GPa}$, $7833 \mathrm{~kg} / \mathrm{m}^{3}$ and 0.29 , respectively. Koller and Busenhart [21] solved the impact problem analytically using the Reissener's theory and compared with experimental results. Lee and Kwak [27] studied the impact problem using the finite element method. The impact responses obtained by the present approach were compared with the analytical, experimental and numerical results reported by Koller [21] and Lee [27]. Fig. 5 and Fig. 6 show the time histories of the contact force and vertical displacement at the impact point of the shell, respectively.

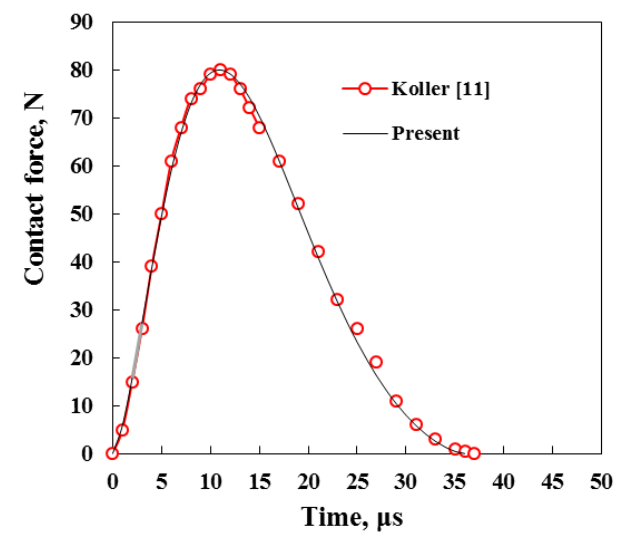

Fig. 5. Contact force of a spherical glass shell impacted by a steel ball

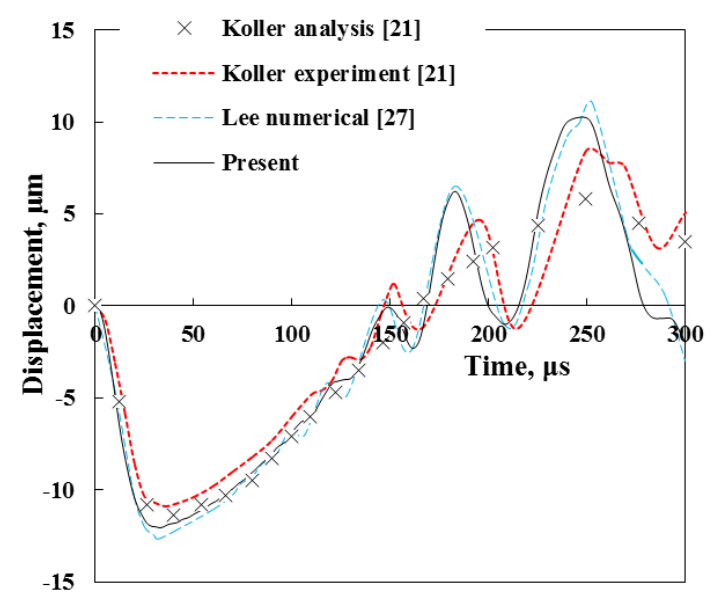

Fig. 6. Displacement at the impact point of the glass shell

It can be observed that present approach exhibits good correlation with the analytical [21], experimental [21] and numerical [27] results in terms of contact force and vertical displacement at the impact point. Next we investigated the influence of different materials of the shell on the contact force. Fig. 7 compares the contact forces exerted on the spherical shells made of steel, aluminum and glass, respectively. The maximum contact forces on the steel, aluminum and glass shells are $149 \mathrm{~N}, 85.5 \mathrm{~N}$ and $80 \mathrm{~N}$, respectively. The contact duration for steel, aluminum and glass shells are 21.8, 33.4 and $35.4 \mu \mathrm{s}$, respectively. It depicts that the contact force is increasing with the increase of the stiffness of the shell, while the contact duration is decreasing.

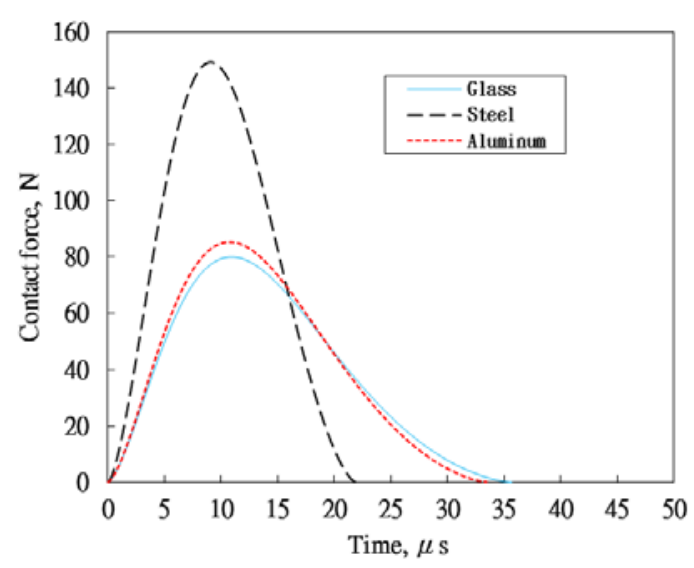

Fig. 7. Comparison of the contact force on different shells

\subsection{Transient responses of the composite laminate spherical shell}

A ball impinged on the apex of a composite laminate T300/934 [0/-45/45/90 $]_{2 s}$ spherical shell with clamped boundary condition. The dimensions of the composite laminate shell are $2.54 \mathrm{~mm}$ in thickness and $330 \mathrm{~mm}$ for the radius. The ball is made of aluminum with the radius of $6.35 \mathrm{~mm}$. The mesh for the finite element analysis of the composite laminate shell is plotted in Fig. 8 with 3200 elements and 4920 nodes. The displacement $w_{g c}(t)$ at the apex of the composite laminate shell under impulse loading $\delta(t)$ is illustrated in Fig. 9.

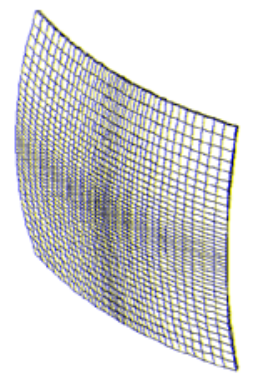

Fig. 8. Mesh for the finite element analysis of the laminate shell

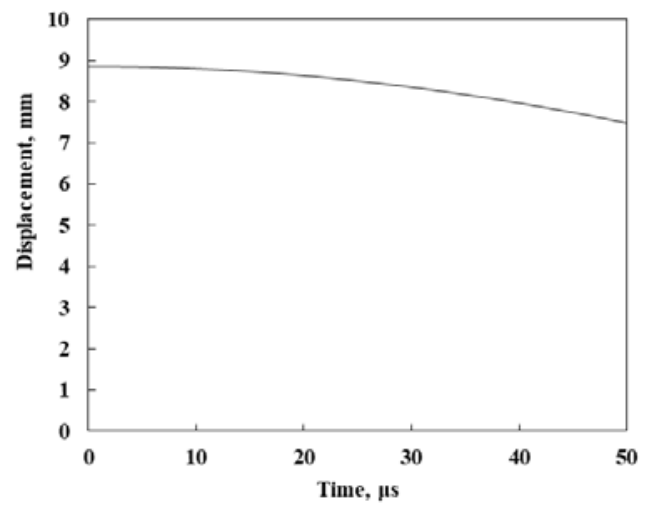

Fig.9. Displacement $w_{g c}(t)$ at the apex of the laminate shell under impulse loading

The influences of the impactor velocity and mass, and stacking sequence of the composite laminate on the impact responses of the composite laminate spherical shell were investigated through a series of parametric studies as follows. 


\subsubsection{Influence of the impactor velocity}

The effect of the impact velocity on the transient responses of the composite laminate shell was investigated. The impact simulations were performed for three different impactor velocities, $38.1 \mathrm{~m} / \mathrm{s}, 25.4 \mathrm{~m} / \mathrm{s}$ and $12.7 \mathrm{~m} / \mathrm{s}$, respectively, while the impactor mass was kept at a constant of $3 \mathrm{~g}$. The procedures to determine the impact force were as follows: (1) substituting the displacement $w_{g c}(t)$ as shown in Fig. 9 and impact velocity $v_{0}$ into intergro-differential Eq. 11 and Eq. 12; (2) utilizing the Runge-Kutta numerical technique to solve the intergrodifferential equations resulting in the determination of the indentation; (3) substituting the indentation of the composite laminate shell into Eq. 3 and Eq. 4 to calculate the contact force. The contact forces exerted on the composite laminate shell by the impactor with three different velocities are plotted in Fig. 10.

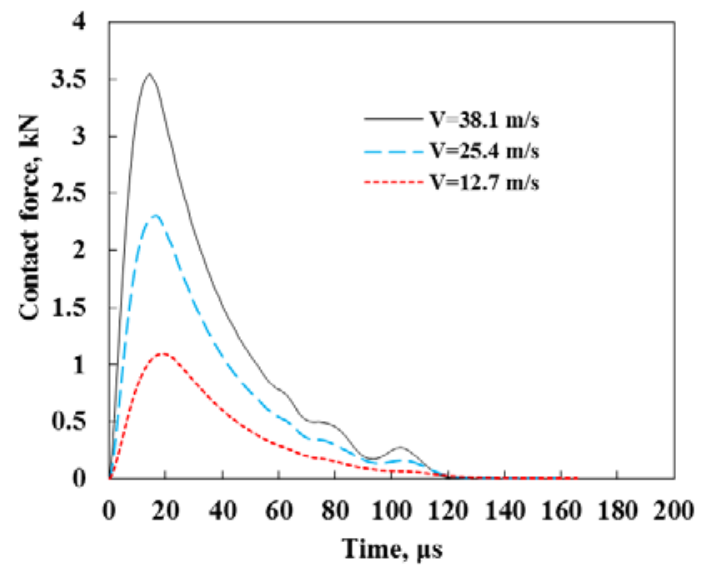

Fig. 10. Contact forces exerted on the composite laminate shell for three different impact velocities

It can be observed that the maximum contact force is linearly increasing with the increase of the impactor velocity as illustrated in Fig. 11.

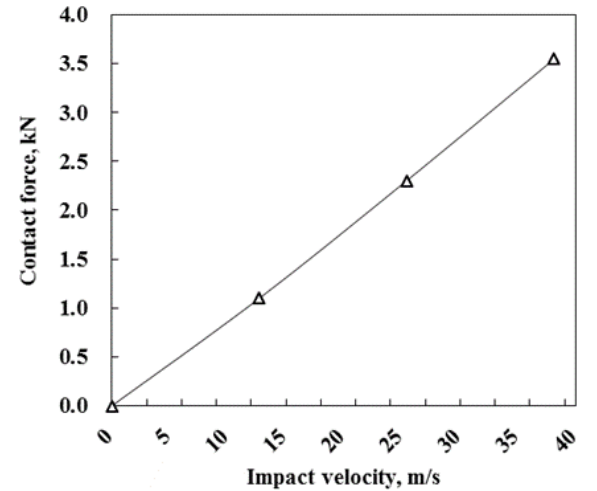

Fig. 11. Maximum contact force versus impact velocity

However, the contact duration between the impactor and composite shell does not change considerably by the impact velocity. The contact force was employed on the apex of the composite laminate shell as an external force. Thereafter, the impact responses of the composite laminate shell were obtained using the ANSYS finite element software. Fig. 12 plots the time dependent of the normal stress $\sigma_{z z}$ at the contact point of the composite laminate shell. It shows that the normal stress is increasing with the increase of the impact velocity.

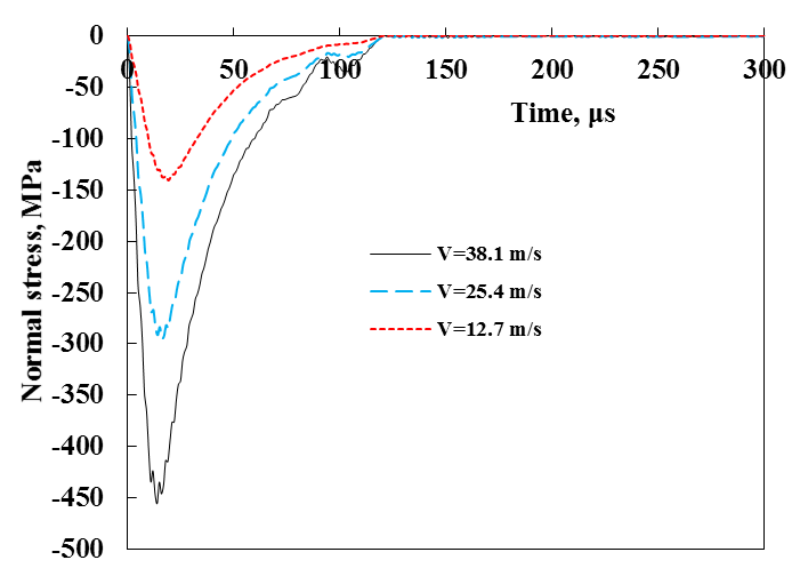

Fig. 12. Normal stress $\sigma_{z z}$ at the top of the laminate shell impacted by three different velocities

\subsubsection{Influence of the impactor mass}

The composite spherical shell was impinged by an aluminum ball with three different masses of $1 \mathrm{~g}, 2 \mathrm{~g}$ and $3 \mathrm{~g}$, respectively. The impactor velocity was kept at a constant of $38.1 \mathrm{~m} / \mathrm{s}$. The contact forces induced by the impactor with three different masses are shown in Fig. 13.

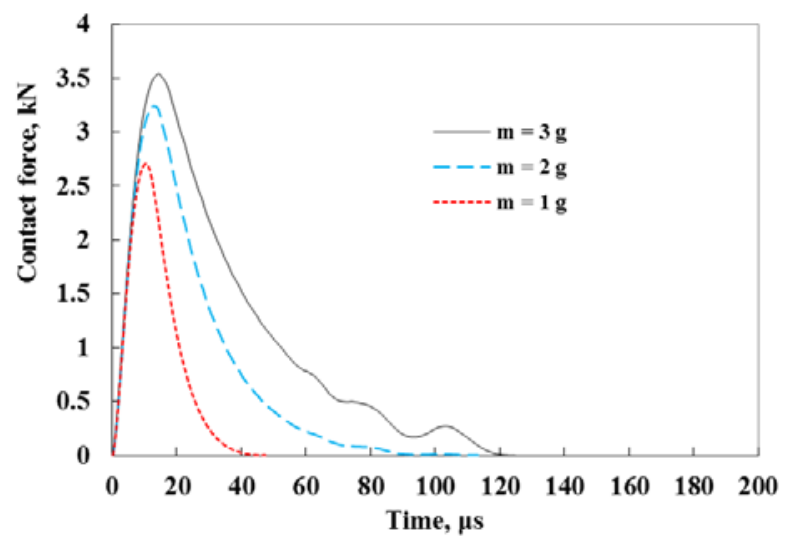

Fig. 13. Contact forces exerted on the composite laminate shell with three different impactor masses

The maximum contact forces for impactor masses of $1 \mathrm{~g}, 2 \mathrm{~g}$ and $3 \mathrm{~g}$ are $2.71 \mathrm{kN}, 3.25 \mathrm{kN}$ and $3.54 \mathrm{kN}$ respectively, and the contact durations are $41.1 \mu \mathrm{s}, 82.7 \mu \mathrm{s}$ and $120.7 \mu \mathrm{s}$, respectively. It appears that the contact duration is significantly affected by the impactor mass while the contact force is less dependent on the impactor mass. Fig. 14 plots the displacement at the contact point of the composite laminate shell. It shows that the displacement is increasing with the increase of the impactor mass.

\subsubsection{Influence of the stacking sequence of the composite laminate}

Five different stacking sequences for the T300/934 composite laminate were prepared to investigate the influence of the ply layup on the impact response. The five different stacking sequences and associated equivalent material properties of the T300/934 composite laminate are listed in Table 2. It can be seen that the equivalent material properties of the composite shell is varying from highly anisotropic material for $[0]_{16}$ to quasi-isotropic material for $\left[0_{2} / 45_{2} /-45_{2} / 0_{2}\right]_{s}$. 


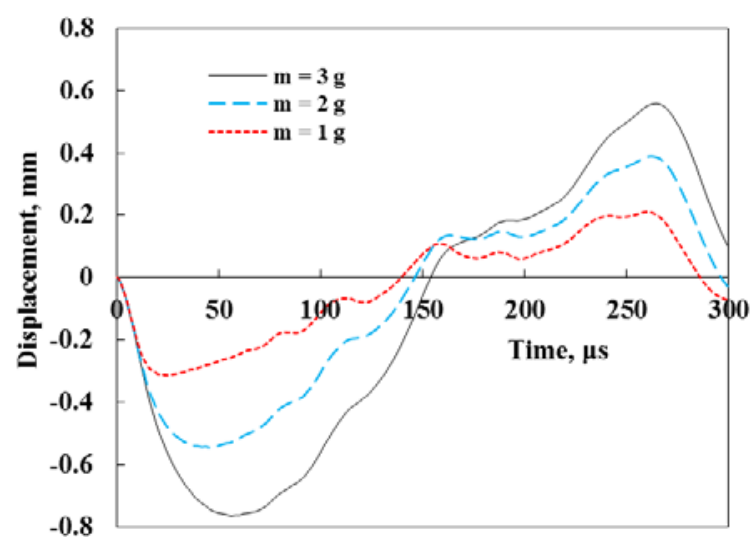

Fig. 14. Displacement at the impact point of the composite laminate shell with three different impactor masses

Table 2. Equivalent material properties of the T300/934 composite laminate with five different stacking sequences

\begin{tabular}{|l|c|c|c|}
\hline \multicolumn{1}{|c|}{ Stacking sequence } & $E_{x x}, \mathrm{GPa}$ & $E_{y y}, \mathrm{GPa}$ & $V_{\mathrm{xy}}$ \\
\hline Case $1[0]_{16}$ & 145.4 & 9.997 & 0.3 \\
\hline Case $2\left[0_{2} / 15_{2} /-15_{2} / 0_{2}\right]_{\mathrm{s}}$ & 133.1 & 10.28 & 0.659 \\
\hline Case $3\left[0_{2} / 30_{2} /-30_{2} / 0_{2}\right]_{\mathrm{s}}$ & 102.5 & 13.22 & 0.989 \\
\hline Case $4\left[0_{2} / 45_{2} /-45_{2} / 0_{2}\right]_{\mathrm{s}}$ & 83.5 & 24.4 & 0.673 \\
\hline Case $5[0 /-45 / 45 / 90]_{2 \mathrm{~s}}$ & 56.5 & 56.5 & 0.305 \\
\hline
\end{tabular}

The composite shell was impacted by an Al ball with mass $3 \mathrm{~g}$ and velocity $38.1 \mathrm{~m} / \mathrm{s}$. Fig. 15 and Fig. 16 plot the time histories of the contact force and vertical displacement at the impact point of the composite shell, respectively.

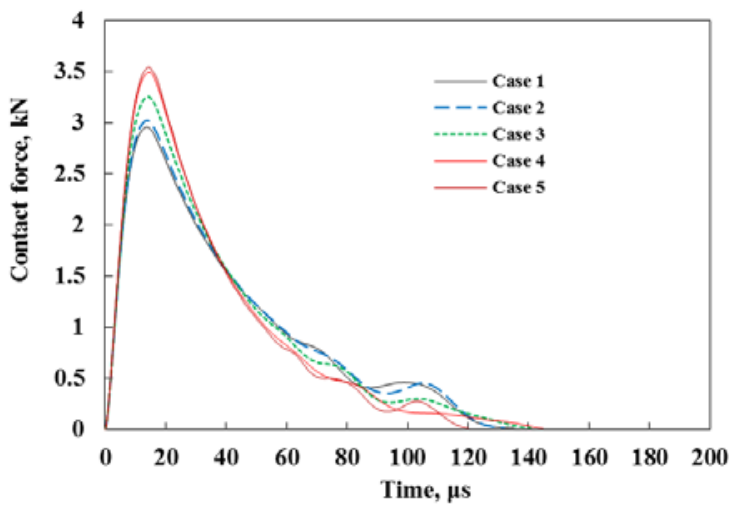

Fig. 15. Comparison of the contact force on the composite shell with different stacking sequence

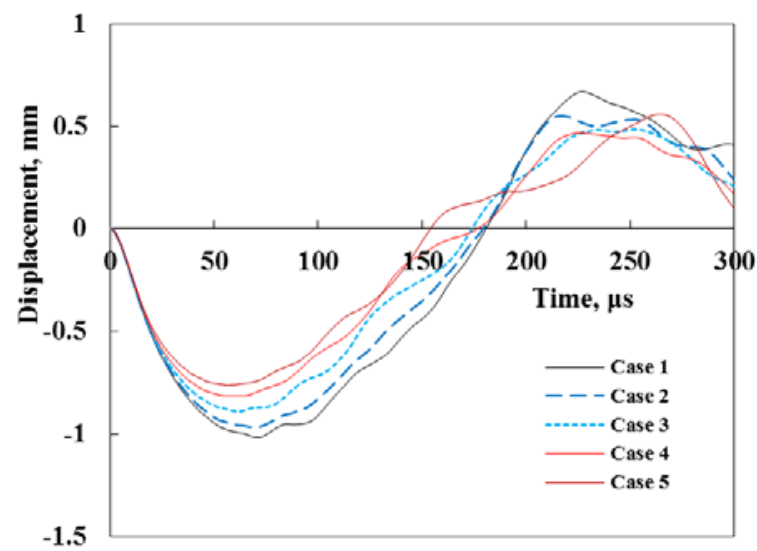

Fig. 16. Comparison of the displacement at the impact point of the composite shell with different stacking sequence
The maximum contact forces for the composite shells with stacking sequences of $[0]_{16}$ and $\left[02_{2} / 45_{2} /-45_{2} / 0_{2}\right]_{s}$ are $2957 \mathrm{~N}$ and $3545 \mathrm{~N}$, respectively. It can be observed that the contact force is increasing as the equivalent material property of the composite shell is changing from highly anisotropic material to quasi-isotropic material due to the variation of the stacking sequence. The vertical displacement at the impact point of the composite shell exhibits in an opposite trend.

\section{CONCLUSIONS}

In this work, a modelling for evaluating the elastic responses of a thin composite spherical shell impacted by a ball was presented. The effects of impactor velocity and mass, and stacking sequences of the composite laminate on the impact response were investigated. A non-linear governing equation in terms of the parameter of indentation was derived basing on the equation of motion and Hertzian contact law. The solution of the governing integro-differential equation was obtained using the numerical technique of Runge-Kutta method, leading to the determination of the contact force. The contact force was employed as an external loading exerted on the top of the thin composite spherical shell. Thereafter, the impact responses of the spherical shell such as the stress and displacement are solved using the finite element analysis. Numerical analyses demonstrate that the contact force is significantly affected by the impactor velocity while contact duration is highly dependent on the impactor mass. Impact responses of the composite laminate shell are significantly affected by the stacking sequence. Stacking sequence of $\left[0_{2} / 45_{2} /-45_{2} / 0_{2}\right]_{s}$ with quasi-isotropic material property exhibits the largest impact force while $[0]_{16}$ with highly anisotropic material property has the lowest impact force. Present work incorporated the analytical expression of the governing equation with the well-known numerical technique Runge-Kutta method, make the impact analysis of composite shell simple and easy to follow.

\section{Acknowledgments}

The authors gratefully acknowledge the financial support provided by Ministry of Science and Technology of Republic of China under grant No. MOST 108-2221-E155-042-MY2 for this work.

\section{REFERENCES}

1. Foo, C.C., Chai, G.B., Seah, L.K. A Model to Predict LowVelocity Impact Response and Damage in Sandwich Composites Composites Science and Technology 68 2008: pp. $1348-1356$.

https://doi.org/10.1016/j.compscitech.2007.12.007

2. Hosseinzadeh, R., Shokrieh, M.M., Lessard, L. Damage Behavior of Fiber Reinforced Composite Plates Subjected to Drop Weight Impacts Composites Science and Technology 66 2006: pp. 61-68.

https://doi.org/10.1016/j.compscitech.2005.05.025

3. Zhao, G.P., Cho, C.D. Damage Initiation and Propagation in Composite Shells Subjected to Impact Composite Structures 78 2007: pp. 91-100.

https://doi.org/10.1016/j.compstruct.2005.08.013

4. Tagarielli, V.L., Deshpande, V.S., Fleck, N.A. The Dynamic Response of Composite Sandwich Beams to 
Transverse Impact International Journal of Solids and Structures 44 2007: pp. 2442-2457.

https://doi.org/10.1016/j.ijsolstr.2006.07.015

5. Schubel, P.M., Luo, J., Daniel, I.M. Low Velocity Impact Behavior of Composite Sandwich Panels Composites: Part A 36 2005: pp. 1389-1396.

https://doi.org/10.1016/j.compositesa.2004.11.014

6. Liu, P.F., Liao, B.B., Jia, L.Y., Peng, X.Q. Finite Element Analysis of Dynamic Progressive Failure of Carbon Fiber Composite Laminates Under Low Velocity Impact Composite Structures 149 2016: pp. 408-422. https://doi.org/10.1016/j.compstruct.2016.04.012

7. Liao, B.B., Liu, P.F. Finite Element Analysis of Dynamic Progressive Failure of Plastic Composite Laminates under Low Velocity Impact Composite Structures 159 2017: pp. $567-578$. https://doi.org/10.1016/j.compstruct.2016.09.099

8. He, W., Guan, Z.D., Li, X., Liu, D.B. Prediction of Permanent Indentation due to Impact on Laminated Composites Based on an Elasto-Plastic Model Incorporating Fiber Failure Composite Structures 96 2013: pp. $232-242$. https://doi.org/10.1016/j.compstruct.2012.08.054

9. Choi, I.H. Finite Element Analysis of Low-Velocity Impact Response of Convex and Concave Composite Laminated Shells Composite Structures 186 2018: pp. 210-220. https://doi.org/10.1016/j.compstruct.2017.11.090

10. Zhang, C., Duodu, E.A., Jinan Gu, J. Finite Element Modeling of Damage Development in Cross-Ply Composite Laminates Subjected To Low Velocity Impact Composite Structures 173 2017: pp. 219-227. https://doi.org/10.1016/j.compstruct.2017.04.017

11. Zhang, J.K., Zhang, $\mathbf{X}$. Simulating Low-Velocity Impact Induced Delamination In Composites by A Quasi-Static Load Model with Surface-Based Cohesive Contact Composite Structures 125 2015: pp. 51-57. https://doi.org/10.1016/j.compstruct.2015.01.050

12. Habibi, M., Laperrirea, L., Hassanabadi, H.M. Influence of Low-Velocity Impact on Residual Tensile Properties of Nonwoven Flax/Epoxy Composite Composite Structures 186 2018: pp. 175-182.

https://doi.org/10.1016/j.compstruct.2017.12.024

13. Puech, L., Ramakrishnan, K.R., Moigne, N.L., Corn, S., Slangen, P.R., Duc, A.L., Boudhani, H., Bergeret, A. Investigating the Impact Behaviour of Short Hemp Fibres Reinforced Polypropylene Biocomposites through High Speed Imaging and Finite Element Modelling Composites Part A 109 2018: pp. 428-439. https://doi.org/10.1016/j.compositesa.2018.03.013

14. Soto, A., González, E.V., Maimí, P., Martín de la Escalera, F., Sainz de Aja, J.R., Alvarez, E. Low Velocity Impact and Compression after Impact Simulation of Thin Ply Laminates Composites Part A 109 2018: pp. 413-427.

https://doi.org/10.1016/j.compositesa.2018.03.017

15. Abir, M.R., Tay, T.E., Ridha, M., Lee, H.P. Modelling Damage Growth in Composites Subjected to Impact and
Compression after Impact Composite Structures 168 2017: pp. $13-25$.

https://doi.org/10.1016/j.compstruct.2017.02.018

16. Gliszczynski, A. Numerical and Experimental Investigations of The Low Velocity Impact in GFRP Plates Composites Part B 138 2018: pp. 181-193.

https://doi.org/10.1016/j.compositesb.2017.11.039

17. Xiao, S., Chen, P., Ye, Q. Prediction of Damage Area in Laminated Composite Plates Subjected to Low Velocity Impact Composites Science and Technology 98 2014: pp. $51-56$.

https://doi.org/10.1016/j.compscitech.2014.04.016

18. Bertona, T., Najafi, F., Singh, C.V. Development and Implementation of A Multi-Scale Model for Matrix MicroCracking Prediction in Composite Structures Subjected to Low Velocity Impact Composites Part B 168 2019: pp. $140-151$.

https://doi.org/10.1016/j.compositesb.2018.12.033

19. Balakrishnan, V.S., $\quad$ Wartig, K., $\quad$ Tsombanis, N., Seidlitz, H. Influence of Processing Parameters on the Impact Behaviour of Glass/Polyamide-6 Composite Composites Part B 159 2019: pp. 292-299. https://doi.org/10.1016/j.compositesb.2018.09.064

20. Hamamousse, K., Sereir, Z., Benzidane, R., Gehring, F., Gomina, M., Poilâne, C. Experimental and Numerical Studies on the Low-Velocity Impact Response of Orthogrid Epoxy Panels Reinforced with Short Plant Fibers Composite Structures 211 2019: pp. 469-480. https://doi.org/10.1016/j.compstruct.2019.01.005

21. Koller, M.G., Busenhart, M. Elastic Impact of Spheres on Thin Shallow Spherical Shells International Journal of Impact Engineering 4 1986: pp. 11-21. https://doi.org/10.1016/0734-743X(86)90024-2

22. Her, S.C., Liao, C.C. Impact Analysis of Composite Laminate Shell Structures Applied Mechanics and Materials 764-765 2015: pp. 1185-1188. https://doi.org/10.4028/www.scientific.net/AMM.764765.1185

23. Tan, T.M., Sun, C.T. Use of Statical Indentation Laws in the Impact Analysis of Laminated Composite Plates Journal of Applied Mechanics 52 1985: pp. 6-12. https://doi.org/10.1115/1.3169029

24. Chandrashekhara, K., Schroeder, T. Nonlinear Impact Analysis of Laminated Cylindrical and Doubly Curved Shells Journal of Composite Materials 29 1995: pp. $2160-2179$. https://doi.org/10.1177/002199839502901604

25. Yang, S.H., Sun, C.T. Indentation Law for Composite Laminates ASTM STP 787 1982: pp. 425-449. https://doi.org/10.1520/STP28494S

26. Wu, H.T., Chang, F. Transient Dynamic Analysis of Laminated Composite Plates Subjected to Transverse Impact Computers \& Structures 31 1989: pp. 453-466. https://doi.org/10.1016/0045-7949(89)90393-3

27. Lee, D.I., Kwak, B.M. An Analysis of Low-velocity Impact of Spheres on Elastic Curved-shell Structures International Journal of Solids Structures 30 1993: pp. 2879-2893. https://doi.org/10.1016/0020-7683(93)90201-H

(c) Her et al. 2022 Open Access This article is distributed under the terms of the Creative Commons Attribution 4.0 International License (http://creativecommons.org/licenses/by/4.0/), which permits unrestricted use, distribution, and reproduction in any medium, provided you give appropriate credit to the original author(s) and the source, provide a link to the Creative Commons license, and indicate if changes were made. 